\title{
PENGARUH PENERAPAN MODEL PEMBELAJARAN \\ INTERACTIVE CONCEPTUAL INTERACTION (ICI) DALAM PEMECAHAN MASALAH MATEMATIKA PESERTA DIDIK
}

\author{
Muhammad Syahrul Kahar ${ }^{*}$, Muhamad Ruslan Layn ${ }^{2}$, Irna Mandasari $^{3}$ \\ ${ }^{1,2,3}$ Program Studi Pendidikan Matematika Universitas Muhammadiyah Sorong \\ *email: muhammadsyahrulkahar@gmail.com
}

\begin{abstract}
The purpose of this study is to determine whether there is the influence of learning outcomes after being given learning using Interactive Conceptual Interaction (ICI) model in solving problem mathematics. This research was conducted at MTs Negeri Model School of Sorong City in class VII D, amounting to 35 students, Instruments used in this research Tests and Observations. The data analysis technique used is N-Gain analysis. Based on the results obtained using SPSS 23.0. It can be seen that the significant value (Sig. 2-tailed) with the ttest is 0.032 and $t_{\text {count }}=-0.777$. Because the value of $t_{\text {count }}$ is in the rejection region $\mathrm{H}_{0}$ because $\mathrm{t}_{\text {count }}<\mathrm{t}_{\text {table }}(-0.777<2.0345)$ then its $\mathrm{H}_{0}$ is rejected. Because the significance value is less than 0.05 , then based on decision making criteria, $\mathrm{H}_{0}$ is rejected. This shows that the provision of Interactive Conceptual Interaction (ICI) learning model influences outcome learning of the students. So it can be seen clearly that Interactive Conceptual Interaction (ICI) learning model has an effect on the problem solving of student math. There is an increase in student problem solving can be seen from $\mathrm{N}$ - Gain in the taught class of 0.55 residing on the medium criterion. From these results it can be concluded that there is the use of Interactive Conceptual Interaction (ICI) learning model, more effective to solving student math problems.
\end{abstract}

Keywords: Interactive Conceptual Interaction, Problem Solving, Learning

\begin{abstract}
ABSTRAK
Tujuan dari penelitian ini adalah untuk mengetahui apakah terdapat pengaruh hasil belajar setelah diberikan pembelajaran mengunakan model Interactive Conceptual Interaction (ICI) dalam pemecahan masalaah matematika. Penelitian ini dilaksanakan di sekolah MTs Negeri Model Kota Sorong pada kelas VII D, yang berjumlah 35 peserta didik, Instrumen yang digunakan dalam penelitian ini Tes dan Observasi. Adapun teknik analisis data yang digunakan yaitu analisis N-Gain. Berdasarkan hasil yang diperoleh dengan menggunakan SPSS 23.0. dapat terlihat bahwa nilai signifikan (Sig. 2-tailed) dengan uji-t adalah 0,032 dan $\mathrm{t}_{\text {hitung }}=-0,777$. Karena nilai $\mathrm{t}_{\text {hitung }}$ berada didaerah penolakan $\mathrm{H}_{0}$ karena $\mathrm{t}_{\text {hitung }}<\mathrm{t}_{\text {tabel }}(-0,777<$ 2,0345) maka $\mathrm{H}_{0}$ nya ditolak.Karena nilai signifikansi lebih kecil dari 0,05 , maka berdasarkan kriteria pengambilan keputusan, $\mathrm{H}_{0}$ ditolak. Ini menunjukkan bahwa pemberian model pembelajaran Interactive Conceptual Interaction (ICI) berpengaruh pada hasil belajar pada peserta didik. Sehingga dapat dilihat jelas bahwa model pembelajaran interactive Conceptual Interaction (ICI) berpengaruh terhadap pemecahan masalah matematika peserta didik. Terdapat peningkatan pemecahan msalah peserta didik dapat dilihat dari $\mathrm{N}$ - Gain pad akelas yang diajar sebesar 0,55 yang berada pada kreteria sedang. Dari hasil tersebut dapat disimpulkan bahwa terdapat pengunaan model pembelajaran Interactive Conceptual Interaction (ICI), lebih efektif terhadap pemecahan masalah matematika Peserta didik.
\end{abstract}

Kata kunci: Interactive Conceptual Interaction, Pemecahan Masalah, Belajar 


\section{PENDAHULUAN}

Fauziah, 2010:2 menyatakan bahwa tahapan pertama dalam pemecahan masalah adalah memahami masalah matematika itu sendiri. Berkaitan dengan hal tersebut maka seseorang telah memiliki kemampuan pemahaman terhadap konsepkonsep matematika maka ia mampu menggunakannya untuk pemecahan masalah. Sebaliknya jika seseorang dapat memecahkan masalah maka orang tersebut harus memiliki kemampuan pemahaman terhadap konsep-konsep matematika yang telah dipelajari sebelumnya.

Dari hasil observasi di MTs Negeri Model Kota Sorong, guru masih menggunakan metode konvensional sehingga masih banyak peserta didik yang tidak memperhatikan atau mengikuti pelajaran dengan baik. Pada saat guru menjelaskan didepan banyak peserta didik yang bermain sendiri dan sibuk mengobrol dengan teman sebangkunya sehingga suasana dalam kelas menjadi gaduh dan membuat guru serta peserta didik lainya tidak bisa berkonsentrasi dalam menerima pelajaran.

Berdasarkan masalah di atas maka perlu diadakannya pemilihan model pembelajaran sehingga peserta didik turut berperan aktif dalam proses belajar. Oleh karena itu, diperlukan model pembelajaran yang tepat, salah satu model pembelajaran yang akan digunakan untuk membantu peserta didik dalam memecahkan masalah matematika yaitu model pembelajaran Interactive Conceptual Interaction (ICI). Interactive Conceptual Interaction (ICI) merupakan landasan pembelajaran keterampilan berfikir, artinya model pembelajaran untuk membentuk konsep atau pengertian berdasarkan kemampuan berfikir.

Pemilihan model pembelajaran diharapkan mampu memberikan pola pikir konstruktif, dapat menghubungkan pengetahuan awal dengan temuan - temuan dalam simulasi yang telah dilakukan, kemudian dapat melatih serta menjadikan kebiasaan berfikir kritis dan kreatif bagi peserta didik untuk meningkatkan kerja sama antar anggota kelompok sehingga dapat meningkatkan pemahamannya terhadap konsep yang diajarkan (Kahar, 2017).

Pembelajaran konseptual interaktif atau Interactive Conceptual Interaction (ICI) merupakan ladasan pembelajaran keterampilan berfikir, artinya model pembelajaran untuk membentuk konsep atau pengertian berdasarkan kemampuan berfikir, dalam model pembelajaran ini peserta didik diharapkan mampu membuat pengertian sesuatu setelah melihat data, fakta realitas untuk menghubungkan satu 
dengan yang lainnya sehingga menjadi satu konsep (Sudana dkk. 2014:3).

\section{METODE}

Penelitian ini menggunakan pendekatan kuantitatif Penelitian ini dilaksanakan di sekolah MTs Negeri Model Kota Sorong pada kelas VII D, yang berjumlah 35 peserta didik pada semester ganjil tahun ajaran 2017/2018. Teknik pengambilan sampel random sampling yaitu teknik pengambilan sampel yang memberikan peluang yang sama kepada setiap unsur/anggota populasi untuk dipilih menjadi anggota sampel secara acak.

Instrumen pengumpulan data dalam penelitian ini yaitu : (1) Observasi, (2)Tes, Dalam penelitian ini kemampuan pemecahan masalah peserta didik diukur dengan menggunakan tes berbentuk esai yang terdiri dari 4 soal pemecahan masalah matematika.

Teknik pengumpulan data yang dilakukan dalam penelitian ini adalah observasi dan tes. Dalam kegiatan observasi, peneliti terlibat langsung dalam kegiatan sehari-hari peserta didik yang sedang diamati atau yang digunakan sebagai sumber data penelitian. Data yang diperoleh dari hasil pretest dan posttest dianalisis untuk mengetahui peningkatan kemampuan pemecahan masalah matematika peserta didik. Besarnya peningkatan kemampuan pemecahan masalah matematika peserta didik antara sebelum dan sesudah pemberian perlakuan (treatment) dihitung dengan rumus berikut:

$$
N-\text { Gain }=\frac{\text { skor pos test }- \text { skor pre test }}{\text { SMI-skor pretest }}
$$

Lestari dan Yudhanegara (2015:235). Untuk mengetahui tinggi atau rendahnya nilai N-gain ditentukan berdasarkan kreteria berikut :

\begin{tabular}{cc}
$\begin{array}{l}\text { Tabel 1. Kriteria Nilai } \\
\text { Nilai } \mathbf{N} \text {-gain }\end{array}$ & Kreteria \\
\hline $\mathrm{N}-$ gain $\geq 0,70$ & Tinggi \\
\hline $0,30<\mathrm{N}-$ gain $<0,70$ & Sedang \\
\hline $\mathrm{N}$ - gain $\leq 0,30$ & Rendah
\end{tabular}

Lestari dan Yudhanegara (2015:235).

\section{HASIL DAN PEMBAHASAN}

\section{Hasil Validasi}

Berdasarkan hasil penelitian yang telah dilakukan didapatkan hasil validasi instrumen sebagai berikut:

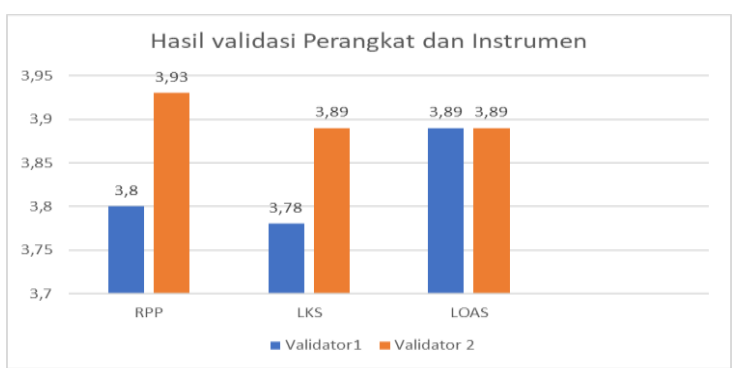

Gambar 1. Hasil Validasi Ahli 
Dari gambar 1, dapat disimpulkan bahwa rata-rata nilai validasi RPP dan LKS dari validator 1 yaitu 3,80 dan 3,78, sedangkan validator 2 yaitu 3,93 dan 3,89 dengan rata-rata maksimunnya 4,00 sehingga RPP dan LKS tersebut dinyatakan valid. Hasil valdasi LOAS yaitu 3,89 dan 3,89 dengan skor maksimum 4,00. Hal ini dapat menunjukan bahwa perangkat dan instrumen memenuhi kevalidan. Uji coba instrumen dilakukan pada kelas uji coba yaitu pada peserta didik kelas VIII D dengan jumlah soal uji coba sebanyak 12 butir soal didapatkan Berdasarkan uji coba soal yang telah dilakukan dengan $\mathrm{N}=34$ dengan taraf signifikan 0,05 didapat $r_{\text {tabel }}=0,338$ soal dapat dikatakan valid jika $r_{\text {hitung }}>0,338$ ( $\mathrm{r}_{\text {hitung }}$ lebih besar dari 0,338).

Dari hasil analisa tersebut dengan taraf $\alpha=0,05$ dari 12 butir soal yang telah diuji cobakan, didapat 8 soal yang dinyatakan valid.

2. Analisis Realibilitas

Sebuah tes dapat dikatakan reliabelitas atau signifikan jika memberikan hasil yang tepat apabila diteskan berkali-kali. Uji reliabilitas dilakukan dengan teknik Alpha (Croncbach's)
Tabel 1. Hasil Uji Realiabilitas

\begin{tabular}{llll}
\hline No & Kreteria & Nomor Soal & Keputusan \\
1 & Valid & $1,2,4,5,7$, & Diambil \\
& & $8,10,11$ & \\
2 & Tidak & $3,6,9,12$ & Dibuang \\
& Valid & \\
\hline \multicolumn{4}{c}{ Sumber : Output SPSS Uji Reabilitas } \\
& \multicolumn{2}{c}{ Dari hasil analisa yang dilakukan }
\end{tabular}
dengan menggunakan software SPSS 23.0. pada tabel 1 diatas dengan uji signifikan dilakukan pada taraf signifikan 0,05. dari 12 soal yang telah diujicobakan, diperoleh 8 soal yang dinyatakan reliabel, dapat dilihat berdasarkan hasil software SPSS 23.0 nilai Cronbach's Alpha sebesar 0,957 yang termasuk pada kategori realiabel sangat tinggi dan nilai $r_{\text {tabel }}$ dari $\mathrm{N}=34$ dengan taraf singnifikan 0,05 didapat $r_{\text {tabel }}$ $=0,339$. Hasil yang didapat yaitu $r_{\text {hitung }}>$ $r_{\text {tabel }}(0,957>0,339)$ sehingga dapat diteruskan pada tahap implementasi.

3. Analisis Lembar Observasi Peserta didik

Untuk memperoleh data mengenai adakah penggaruh model pembelajran Interactive Coceptual Interaction (ICI) pada pemecahan masalah matematika peserta didik pada kelas VII D maka dilakukan observasi. Adapun tabel lembar observasi sebagai berikut: 
Tabel 2. Hasil Observasi Kegiatan

Pembelajaran

\begin{tabular}{ccccc}
\hline No. & $\begin{array}{c}\text { Lembar } \\
\text { Observasi } \\
\text { Peserta } \\
\text { didik }\end{array}$ & $\begin{array}{c}\text { Rata- } \\
\text { Rata }\end{array}$ & Kategori & $\%$ \\
1 & $\begin{array}{l}\text { Pertemuan } \\
\text { pertama }\end{array}$ & 3,63 & sangat baik & 90,75 \\
2 & $\begin{array}{l}\text { Pertemua } \\
\text { kedua } \\
\text { Pertemuan } \\
\text { ketiga }\end{array}$ & 3,21 & sangat baik & 80,25 \\
& 3,58 & sangat baik & 89,5 \\
Rata-rata total & 3,47 & sangat baik & 86,75 \\
\hline
\end{tabular}

Berdasarkan tabel diatas dapat dilihat bahwa nilai rata-rata aktivitas belajar peserta didik pada setiap pembelajaran berada pada kategori sangat baik. Dengan rata-rata pertemuan pertama sebesar 3,63 berada pada kategori baik, pertemuan kedua rata-rata 3,21 berada pada katogori sangat baik, pertemuan ketiga rata-rata 3,58 berada pada kategori sangat baik. Dari tabel diatas juga dapat liha bahwat rata-rata total dari ketiga pertemuan adalah 3,47 dengan kategori sangat baik dan persentase aktivitas peserta didik $86,75 \%$. Sehingga dapat disimpulkan bahwa terdapat beberapa faktor yang mempenggaruhi model pembelajaran Inteactive Conceptual Interaction (ICI) dalam pemecahan masalah matematika peserta didik.

\section{4. $\mathrm{N}-$ Gain}

Hasilnya dianalisis untuk mengetahui penguasaan materi pada pokok bahasan persamaan linear satu variabel. Jumlah soal yang digunakan adalah 8 butir soal uraian. Hasil rata-rata N-Gain dapat dilihat pada hasil rata-rata pretest dan posttest. Nilai tersebut dapat dirumuskan pada hasil $\mathrm{N}$ gain. Dapat dilihat pada tabel berikut :

Tabel 3. Hasil N-Gain

Hasil Nilai Rata-rata Skor Rata-rata

Pretest Postest Maksimal N-Gain $22 \quad 65,06 \quad 100 \quad 0,56$

Nilai N-Gain pada tabel diatas diperoleh dari rata-tata postest adalah $=$ 65,06 dikurang rata-rata pretest adalah $=$ 22 dibagi skor maksimal adalah $=100$ dikurang rata-rata pretest adalah $=22$ sehingga diperoleh hasil $\mathrm{N}-$ Gain $=0,55$, Jadi hasil N-Gain pada kelas yang diajar adalah $=0,55$. Ini menunjukkan bahwa pada kelas yang diajar berada pada interpretasi kategori sedang yang berarti terjadi peningkatan pada hasil belajar peserta didik.

Data yang diperoleh dalam penelitian ini berdistribusi normal dan memiliki varians yg sama, maka dapat dilanjutkan pada uji kesamaan rerata dengan uji t. Berdasarkan kriteria pengujian bahwa $\mathrm{H}_{1}$ 
diterima jika nilai Jika nilai signifikansi lebih kecil dari 0,05 maka $\mathrm{H}_{0}$ ditolak dan Jika nilai signifikansi lebih besar dari 0,05 maka $\mathrm{H}_{1}$ diterima. Pada uji t kelas yang diajar sebesar 0,000, Karena nilai signifikansi lebih kecil dari 0,05, maka berdasarkan kriteria pengambilan keputusan, $\mathrm{H}_{0}$ ditolak. Ini menunjukkan bahwa pemberian model pembelajaran Interactive Conceptual Interaction (ICI) berpengaruh pada hasil belajar pada peserta didik.

Secara garis beasar pembelajaran yang telah dilakukan berjalan dengan baik, sehingga hasil dari analisis yang dilakukan sesuai dengan hipotesis yang telah dipaparkan sebelumnya. Hal ini didukung karena dalam pembelajaran dengan menggunakan model pembelajaran Interactive Conceptual Interaction (ICI) menuntut peserta didik untuk lebih aktif dalam proses pembelajaran. Setelah itu peserta didik mengerjakan soal latihan yang terdapat pada LKS secara berkelompok.

Pembelajaran pada kelas sampel sangat efektif, peserta didik termotivasi untuk mengikuti proses pembelajaran dengan baik. Dengan menggunakan model pembelajaran Interactive Conceptual Interaction (ICI) memudahkan peserta didik dalam memahami materi yang di berikan. Hal ini sejalan dengan penelitian
Khoiri, et.al. (2017) dan Kahar, (2017) menjelaskan bahwa motivasi belajar, minat belajar peserta didik sangat berpengaruh terhadap prestasi belajar yang di peroleh oleh peserta didik tersebut.

Dalam mengerjakan LKS peserta didik diarahkan agar memahami soal LKS yang diberikan, sehingga materi yang diajarkan dapat dipahami oleh seluruh peserta didik, Guru mengarahkan pada setiap kelompok agar membantu teman sekelompoknya yang masih mengalami kesulitan dalam mengerjakan soal LKS. Guru memberikan motivasi agar peserta didik dapat bersemangat dalam mengikuti pembelajran dan dalam mengerjakan soal LKS.

Peserta didik kemudian diarahkan untuk maju kedepan mewakili kelompoknya untuk menjelaskan hasil dari LKS yang telah didiskusikan, dalam hal ini guru memilih peserta didik yang masih belum paham sepenuhnya pada LKS tersebut bertujuan untuk memperkuat pemahaman peserta didik. Kemudian guru dan peserta didik kemudian bersamabersama mengecek hasil diskusi yang telah di presentasikan. Setelah masing-masing peserta didik telah mengecek jawaban masing-masing, maka peserta didik yang memiliki jawaban yang paling banyak benar akan mendapatkan reward. 
Adapun faktor-faktor yang mempengaruhi model pembelajaran Intractive Conceptual Interaction (ICI) dalam pememecahkan masalah matematika diantara sebagai berikut : (1) Faktor Internal, yang menekankan pada faktor dalam diri individu itu sendiri. Faktor yang mempengaruhi kegiatan tersebut adalah faktor psikologis yakni motivasi, perhatian, pengamatan dan tanggapan.; (2) Faktor Eksternal, faktor dari luar individu yakni dimana pencapaian tujuan belajar perlu diciptakan adanya system lingkungan yang kondusif. Hal ini berkaitan dengan faktor dari luar diri peserta didik. Faktor yang mempengaruhi adalah mendapatkan pengetahuan,pehaman konsep dan keterampilan serta pembentukan sikap.

\section{SIMPULAN}

Berdasarkan hasil penelitian diatas dapat disimpulkan bahwa, terdapat pengaruh hasil belajar setelah mengunakan model pembelajaran Interactive Conceptual Interaction (ICI) dalam pemecahan masalaah matematika dapat dilihat dari uji hipotesis $t_{\text {sing }}$ 2-tailed 0,000 $>0,05 \mathrm{H}_{0}$ ditolak. Terdapat faktor-faktor yang mempengaruhi penerapan model pembelajaran Interactive Conceptual Interactive (ICI)

\section{DAFTAR PUSTAKA}

Fauziah, A. 2010. "Peningkatan Kemampuan Pemahaman Dan Pemecahan Masalah Matematika Peserta didik SMP Melalui Strategi React”. Lubuklingau: Jurnal Matematika, 30(1): 1-13.

Kahar, M. S. (2017). Pengembangan Perangkat Pembelajaran Fisika Dengan Menggunakan Model Pembelajaran Kooperatif Tipe STAD. JIPF (Jurnal Ilmu Pendidikan Fisika), 2(2), 42-49.

Kahar, M. S. (2017). Analisis Minat Belajar Mahasiswa Terhadap Penggunaan Alat Peraga Neraca Cavendish. SEJ (Science Education Journal), 1(2), 73-83.

Khoiri, A., Nasihah, U., \& Kahar, M. S. (2017). Analisis Prestasi Belajar Fisika Berpendekatan SETS di Tinjau dari Motivasi Berprestasi. Jurnal Riset dan Kajian Pendidikan Fisika, 4(2), 83-89

Lestari, K, E. \& Yudhanegara, M, R. 2015. Penelitian Pendidikan Matematika. Bandung: PT. Refika Aditama.

Sudana, D, N., Kusumayani, K, D., \& Dibia, I. 2014. "Pengaruh Model(ICI) Interactive Conceptual Interaction Terhadap Prestasi Belajar IPS Peserta didik Kelas IV SD". Bali: Jurnal IPS, 2(1): 1-10. 